Supporting information:

\title{
Textured Manganite Films Anywhere
}

Alexis Boileau$^{1 \S}$, Marie Dallocchio ${ }^{1 \S}$, Florent Baudouin ${ }^{2}$, Adrian David $^{1}$, Ulrike Lüders ${ }^{1}$, Bernard Mercey ${ }^{1}$, Alain Pautrat ${ }^{1}$, Valérie Demange ${ }^{2}$, Maryline Guilloux-Viry ${ }^{2}$, Wilfrid Prellier $^{1}$, Arnaud Fouchet ${ }^{1 *}$

1 NORMANDIE UNIV, ENSICAEN, UNICAEN, CNRS, CRISMAT, 14000 CAEN, France

2 ISCR, Univ Rennes, CNRS, ISCR - UMR 6226, ScanMAT - UMS 2001, F-35000 Rennes, France

* Corresponding author:

E-mail: arnaud.fouchet@ensicaen.fr

$\S:$ A.B and M.D contributed equally to this work

Keywords: LSMO thin films, nanosheets, electrical properties, magnetic properties, glass substrate 


\section{1/ Transmission electron microscopy and atomic force microscopy characterizations of the nanosheets (NS):}

The nanosheets were observed by transmission electron microscopy with the help of a Jeol 2100 instrument operating at $200 \mathrm{kV}$ and equipped with an energy dispersive X-ray spectrometer (EDXS, Oxford Aztec $80 \mathrm{~mm} 2 \mathrm{SDD}$ device). Prior to this observation, a drop of the colloidal nanosheets suspension was deposited on a holey carbon copper grid. The TEM brightfield image displays several rectangular nanosheets with size lying between $200 \mathrm{~nm}$ to 3 $\mu \mathrm{m}$ (Figure S1). The composition determined by Energy Dispersive Spectroscopy (EDS) analysis performed on several nanosheets is around $\mathrm{Ca}_{1.8} \mathrm{Nb}_{3} \mathrm{O}_{10}$.

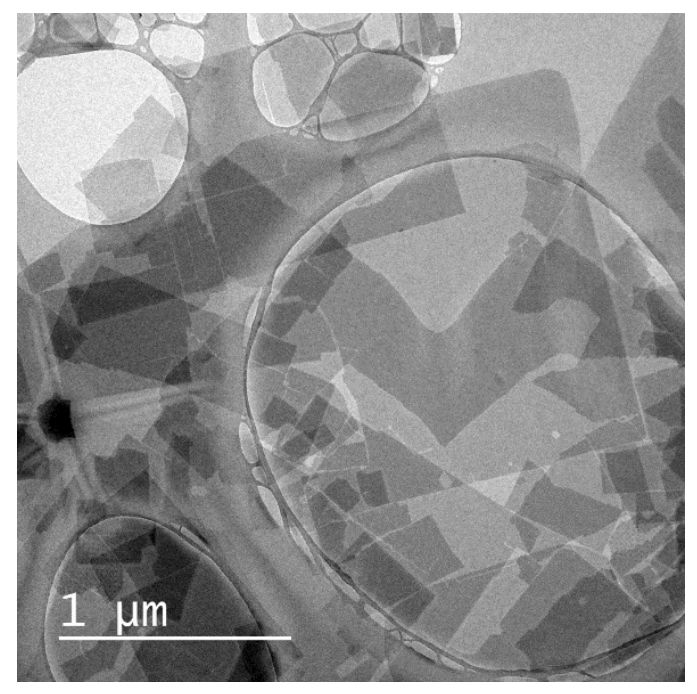

Figure S1. TEM brightfield micrograph of tetra(n-butyl)ammonium ${ }^{+} \mathrm{Ca}_{2} \mathrm{Nb}_{3} \mathrm{O}_{10^{-}}$nanosheets.

A sample of as-deposited nanosheets on glass substrate was characterized by atomic force microscopy in tapping mode (more technical details are given in the main text in experimental section). Figure S2 (a) displays a $5 \times 5 \mu \mathrm{m}^{2}$ AFM image of the surface. Dark areas correspond to the apparent glass substrate surface. The AB profile (b) extracted from the AFM image (a) gives the thickness of one nanosheet. The value is estimated to be $2.6 \mathrm{~nm}$ (nanosheet unit). The CD profile (c) exhibits the superposition of 3 nanosheets leading to locally a maximal thickness of $8 \mathrm{~nm}$. The AFM image processing gives a surface coverage by the nanosheets of $90 \%$ (d) (the treatment of the image were done by Image J software). 

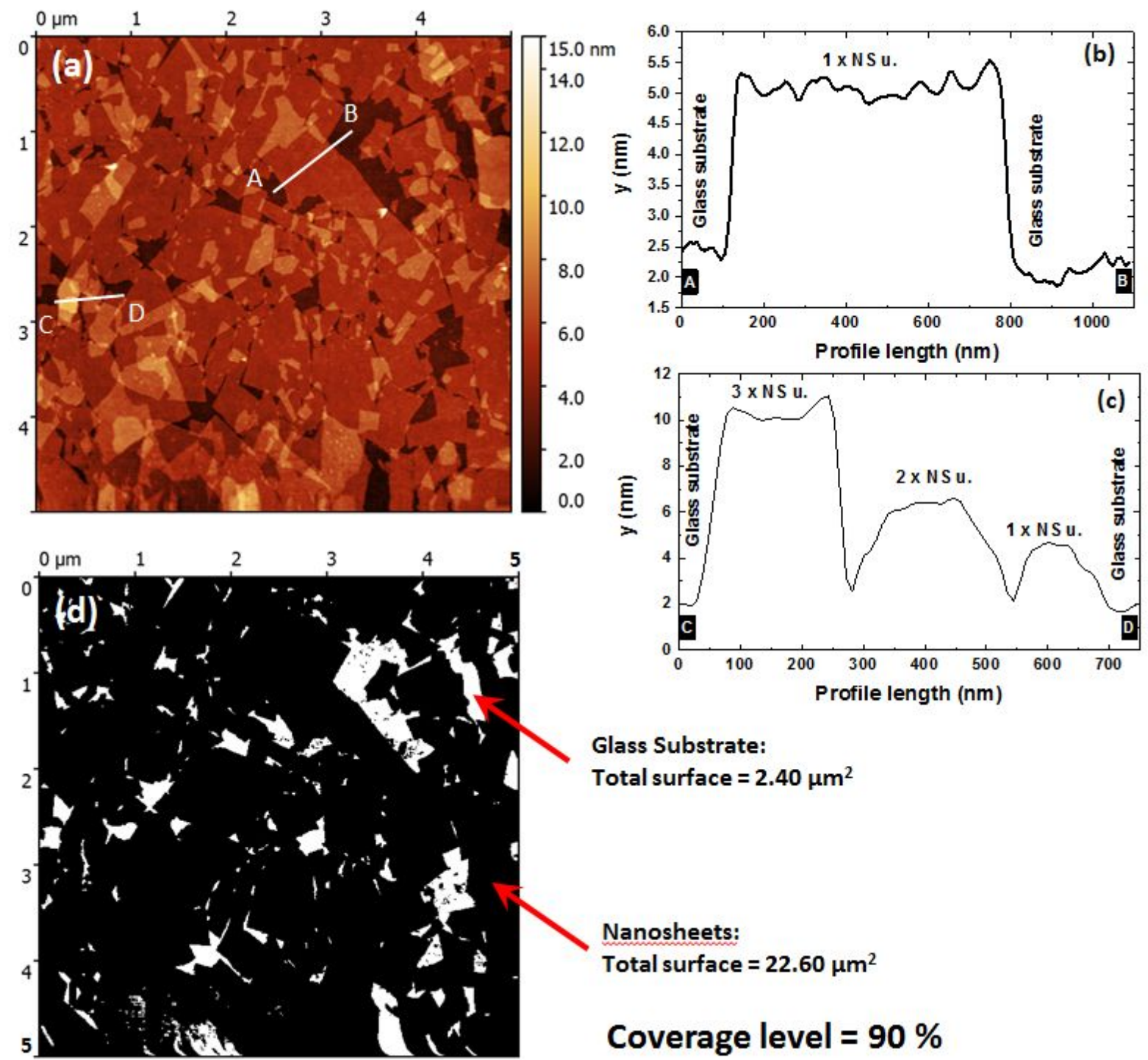

Glass Substrate:

Total surface $=\mathbf{2 . 4 0} \boldsymbol{\mu \mathrm { m } ^ { 2 }}$

Nanosheets:

Total surface $=22.60 \mu \mathrm{m}^{2}$

Coverage level $=90 \%$

Figure S2. (a) $5 \times 5 \mu \mathrm{m}^{2}$ AFM images of nanosheets deposited on glass substrate and (b and c) associated profiles taken at different places. The nanosheet thickness is estimated to be 2.6 nm (NS unit). (d) Estimation of the covered surface by the nanosheets.

\section{2/ RHEED study of the LSMO films grown onto STO substrates}

The RHEED patterns of LSMO films deposited on $\mathrm{SrTiO}_{3}$ single crystal along the [100] and [110] azimuths are presented in Figure S3 (a) and (b), respectively. For more details, refer to Mercey et al. ${ }^{1}$. 

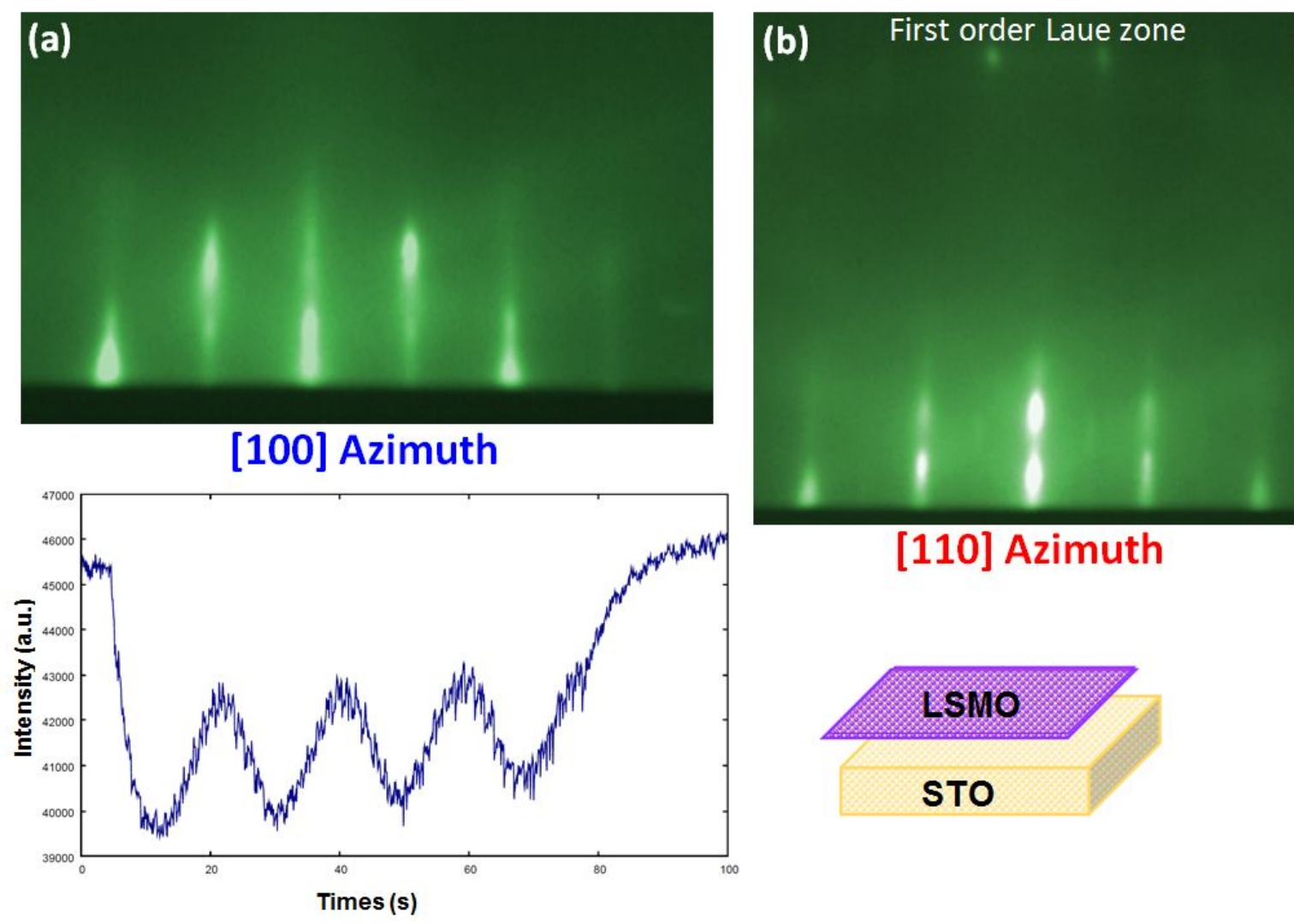

\section{[110] Azimuth}

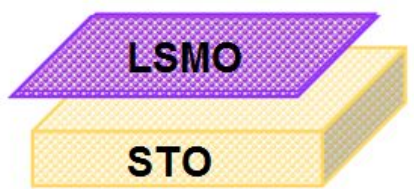

Figure S3. RHEED patterns of a LSMO film deposited on a $\mathrm{SrTiO}_{3}$ [001]-oriented substrate with the electron beam along the [100] azimuth (a) and the [110] azimuth (b). RHEED oscillations of the pure specular beam recorded during the growth of LSMO thin film on $\mathrm{SrTiO}_{3}$.

The out-of-plane lattice parameter determined from the high resolution $\theta-2 \theta$ scans (Figure S4) is $c=0.383(8)$ and $0.385(2) \mathrm{nm}$ at 550 and $645^{\circ} \mathrm{C}$, respectively. The observation of finite size fringes indicates a good quality of the growth and their position is in agreement with a film thickness of $40 \mathrm{~nm}$. 

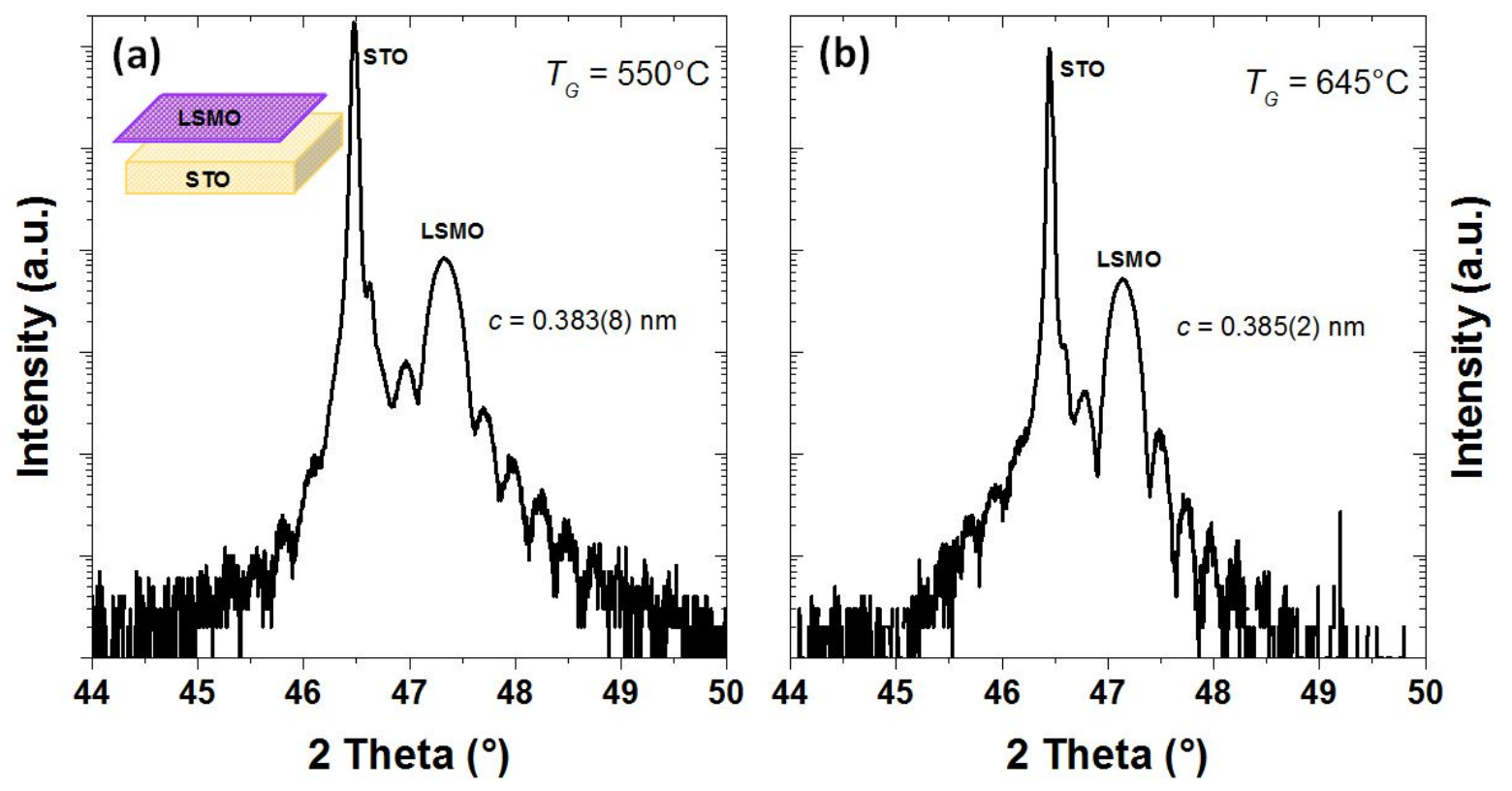

Figure S4. High resolution $\theta-2 \theta$ diffractograms of LSMO films grown on $\mathrm{SrTiO}_{3}$ substrates at $550^{\circ} \mathrm{C} \mathrm{(a)} \mathrm{and} 645^{\circ} \mathrm{C} \mathrm{(b).}$ 


\section{3/ Growth of LSMO on NS}

The RHEED pattern of a LSMO film deposited at $645^{\circ} \mathrm{C}$ on a glass substrate covered by $\mathrm{Ca}_{2} \mathrm{Nb}_{3} \mathrm{O}_{10}{ }^{-}$nanosheets is represented in Figure $\mathrm{S} 5$ (a). Whatever the orientation of the incident electron beam with respect to the glass substrate, the same pattern is observed. This pattern is the superimposition of the patterns observed along the [100] and the [110] azimuths of a single crystal Figure S3 (a) and (b). This indicates that a random in-plane orientation of the LSMO is observed in agreement with a random in-plane orientation of the NS. This pattern also indicates a 3D-like growth mode, the streaks of the 2D growth being replaced by spots.

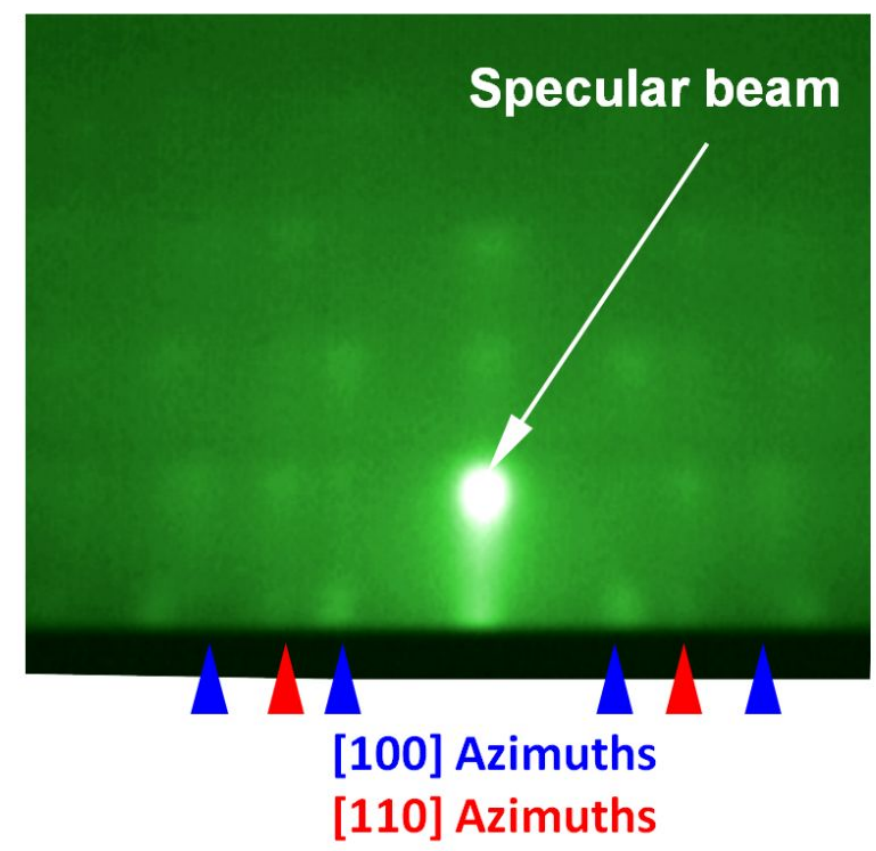

Figure S5. RHEED patterns of a LSMO films deposited on NS/GS at $645^{\circ} \mathrm{C}$ with wellmarked [100] and [110] directions. 

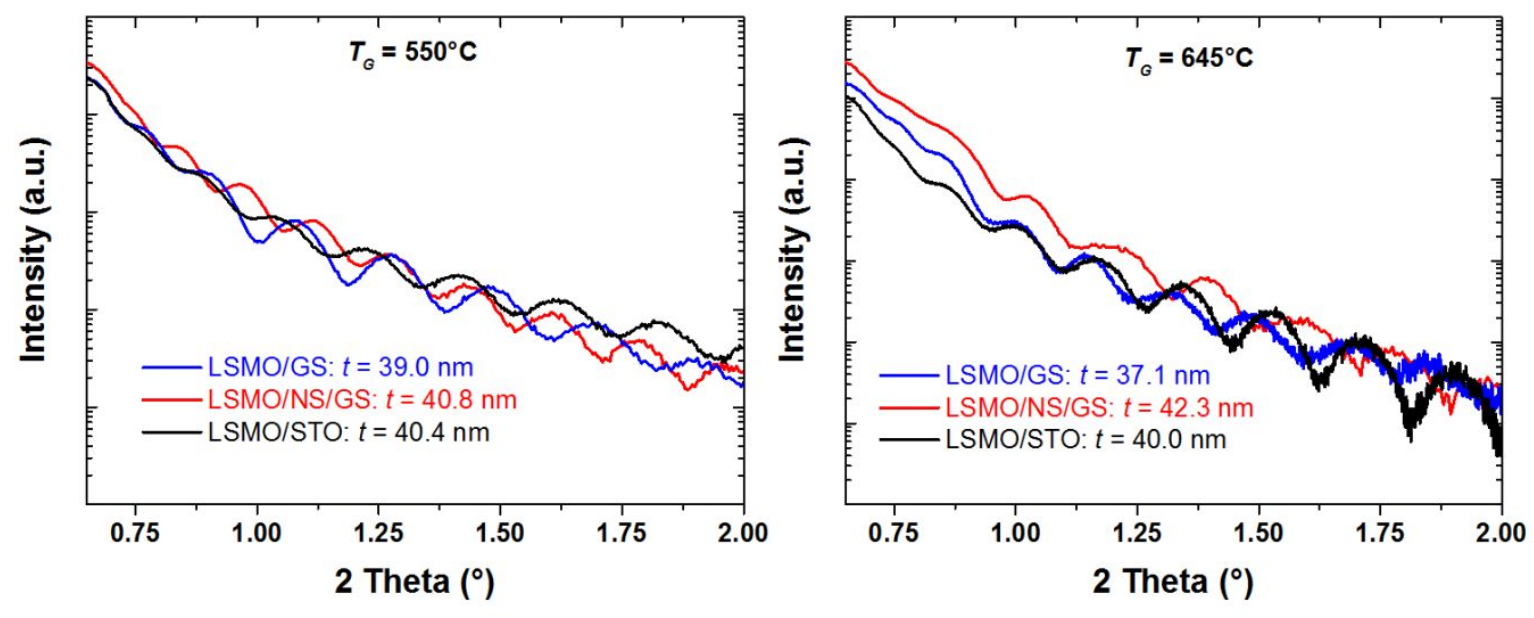

Figure S6. Thickness $(t)$ oscillations measured by X-ray reflectometry for LSMO thin films $(t$ $\sim 40 \mathrm{~nm}$ ) grown on different substrates at $550^{\circ} \mathrm{C}$ and $645^{\circ} \mathrm{C}$. 

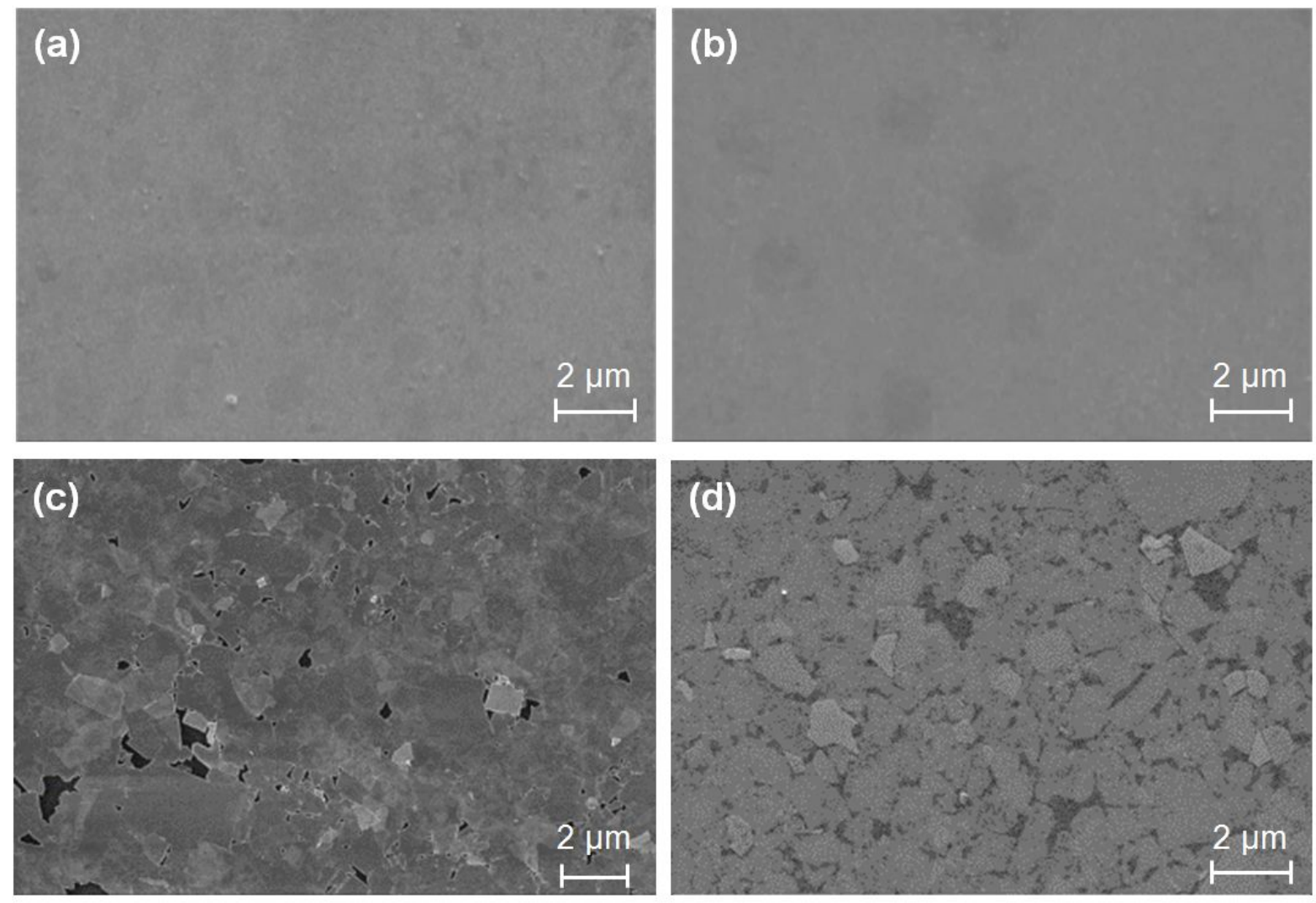

Figure S7. SEM micrographs of LSMO thin films deposited onto GS at $550^{\circ} \mathrm{C}$ (a) and $645^{\circ} \mathrm{C}$ (b) and onto NS/GS at $550^{\circ} \mathrm{C} \mathrm{(c)} \mathrm{and} 645^{\circ} \mathrm{C}(\mathrm{d})$. 
c/ Atomic force microscopy
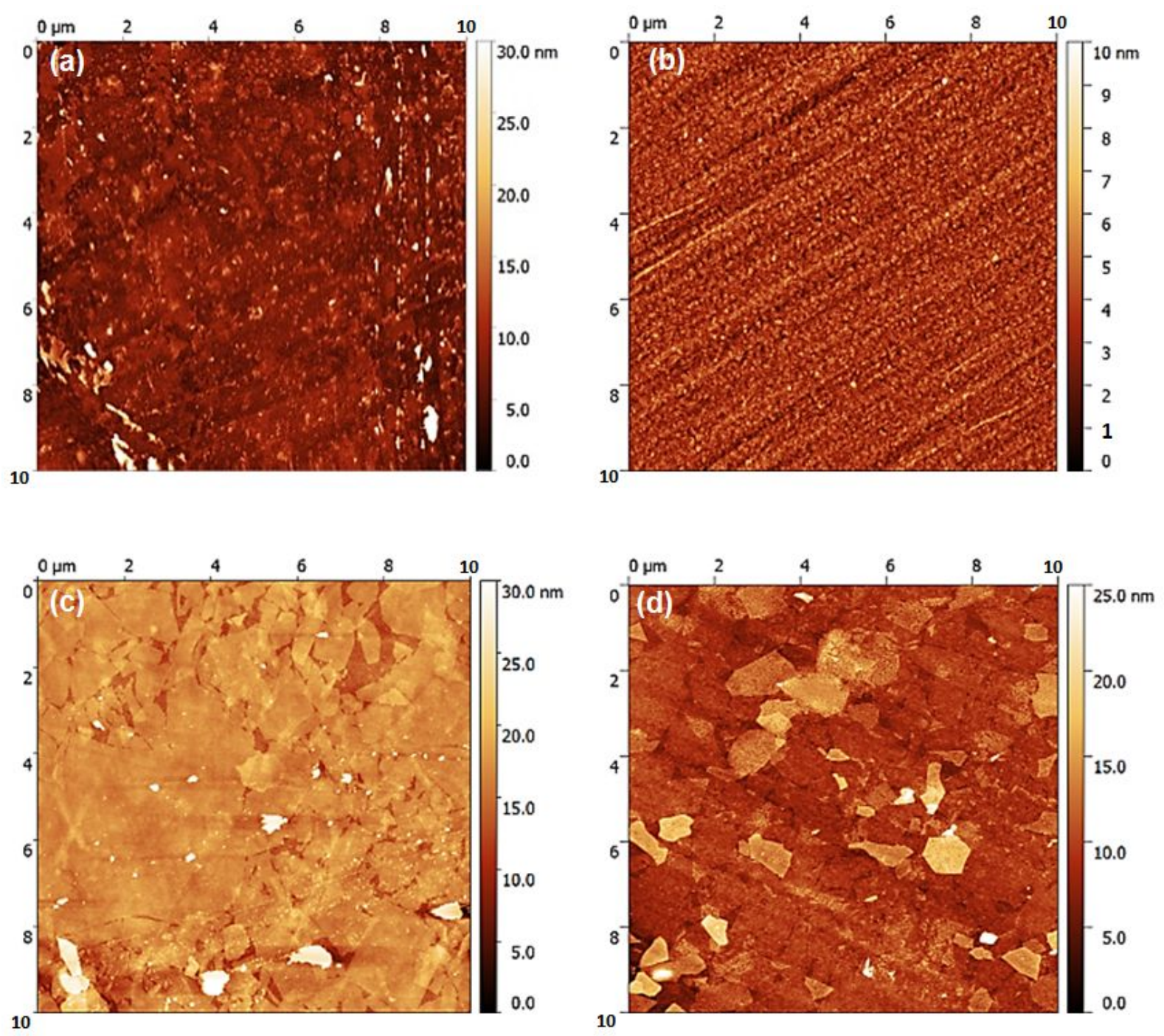

Figure S8. (a) $10 \times 10 \mu \mathrm{m}^{2}$ AFM images of LSMO films grown on GS (a-b) and NS/GS (c-d) at $550^{\circ} \mathrm{C}$ and $645^{\circ} \mathrm{C}$ respectively. 

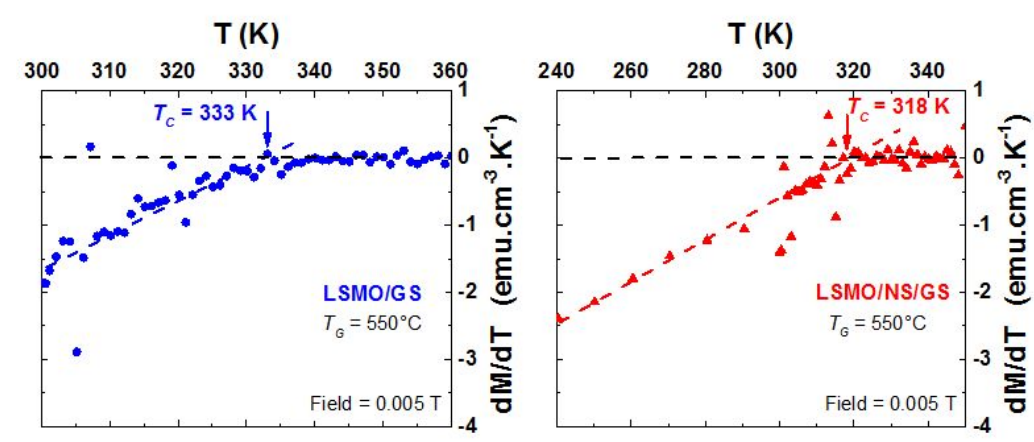

$\mathrm{T}(\mathrm{K})$

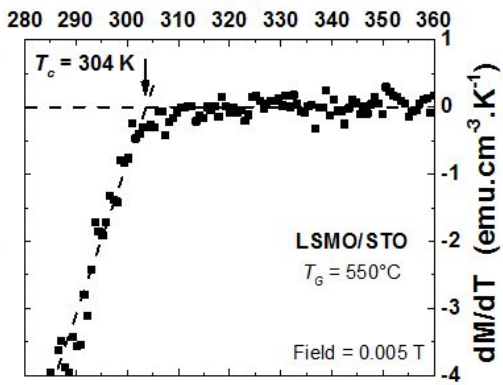

$\mathbf{T}(\mathrm{K})$

$\mathrm{T}(\mathrm{K})$

$\mathrm{T}(\mathrm{K})$
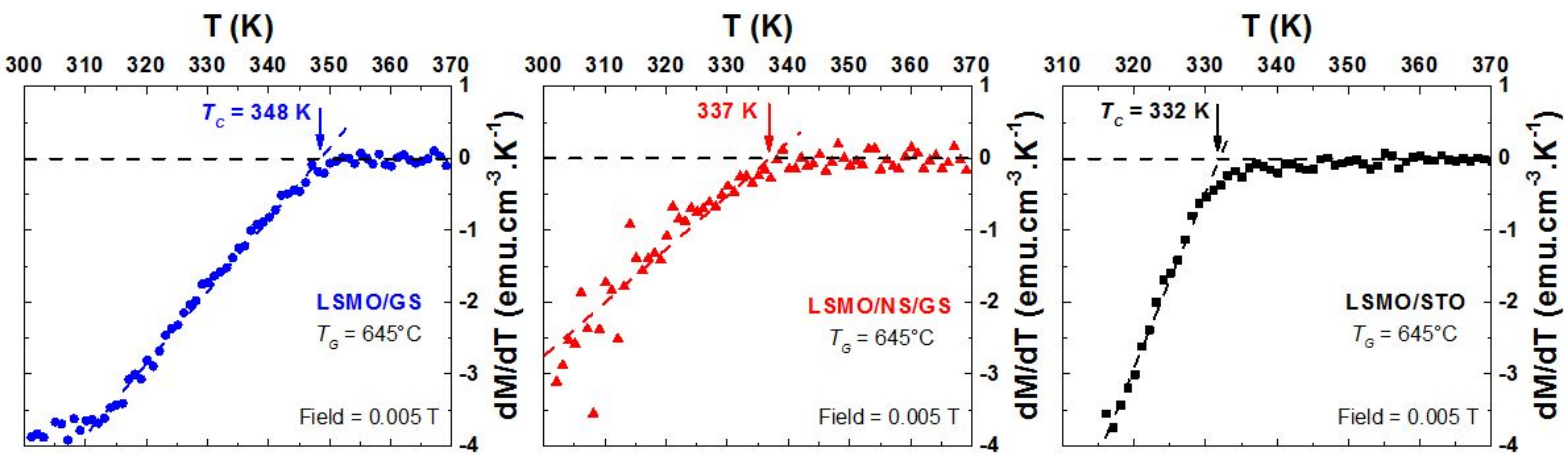

Figure S9. First derivative of the magnetization curves of LSMO films acquired at $0.005 \mathrm{~T}$. $T_{C}$ is taken when the linear fit below the transition intercepts the zero axis.

e/ Transport properties at low temperature
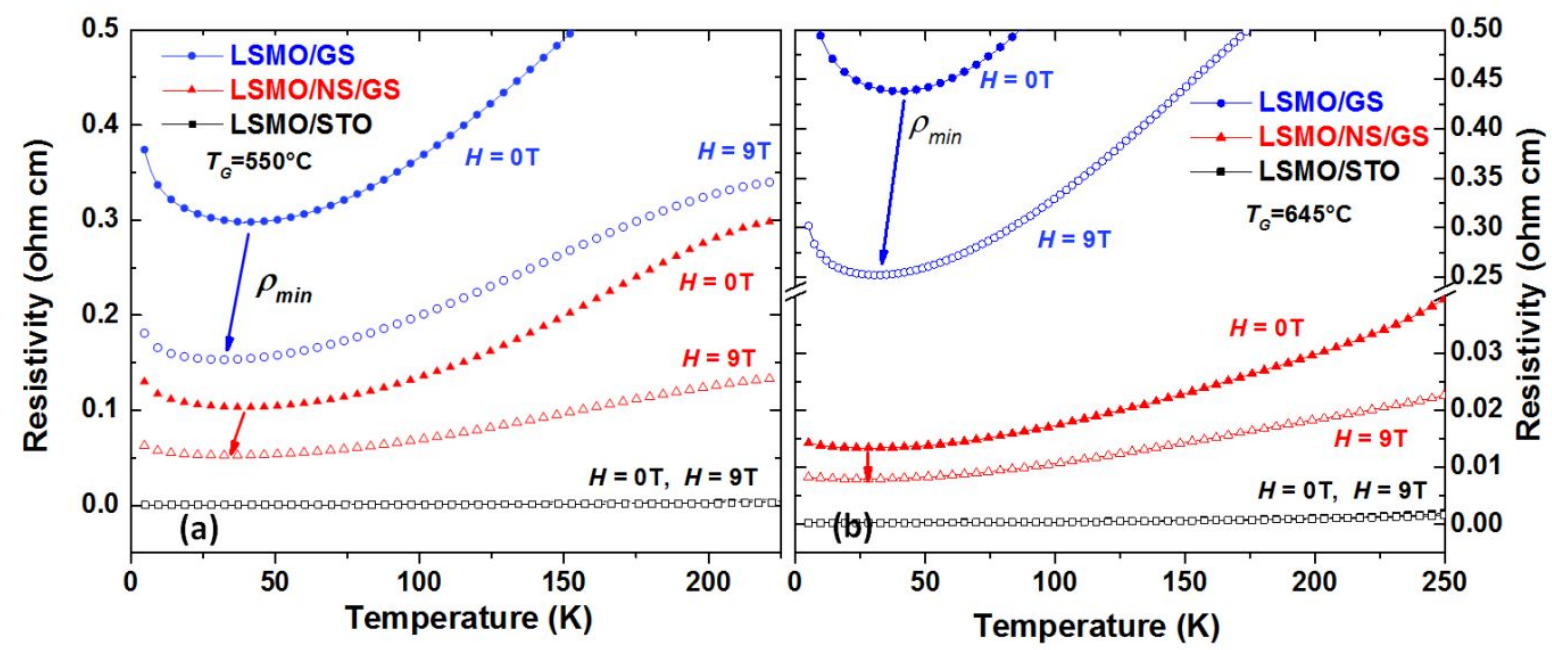

Figure S10. Temperature dependence of the resistivity at low temperature of LSMO films measured in parallel configuration at $H=0 \mathrm{~T}$ and $9 \mathrm{~T}$ for $T_{G}=550^{\circ} \mathrm{C} \mathrm{(a)} \mathrm{and} 645^{\circ} \mathrm{C} \mathrm{(b)} \mathrm{for}$ different substrates (STO, NS/GS, GS). 


\section{References}

[1] Mercey, B.; David, A.; Copie, O.; Prellier, W. Monitoring the Growth of $\mathrm{SrTiO}_{3}$ and $\mathrm{La}_{0.66} \mathrm{Sr}_{0.33} \mathrm{MnO}_{3}$ Thin Films Using a Low-pressure Reflection High Energy Electron Diffraction System. Physica B: Condensed Matter 2016, 503, 100-105. 